\title{
Diálogo entre arquitetura e arte sacra
}

\author{
UBIRATAN J. A. SILVA I
}

\section{Introdução}

A ARQUITETURA tem como finalidade a criação de espaços para abrigar as diversas dimensões humanas - a moradia, o trabalho, a escola. $\mathrm{O}$ trabalho do arquiteto é projetar esses espaços.

Por vocação ou sorte, a construção de espaços religiosos acabou se tornando um dos aspectos mais relevantes de minha atividade profissional, num caminho que já dura algumas décadas. Meu primeiro trabalho foi nos idos de 1983, no projeto inicial do Mosteiro da Ressurreição em Ponta Grossa no Paraná, uma fundação dos monges beneditinos do Mosteiro de São Bento de São Paulo.

A arquitetura religiosa, porém, possui certas particularidades, sendo a principal delas a relação com o sagrado. Para aqueles que seguem alguma religião, o edifício religioso é um espaço em que o sagrado se manifesta e o torna qualitativamente distinto do mundo profano que o rodeia (Eliade, 1992). A igreja, construção que não deixa de ter sua existência material e social específica, adquire na consagração também um caráter sacro, no qual o divino se manifesta e irrompe de maneira preferencial e única.

No caso das igrejas, espaços sagrados por excelência dos católicos, isso significa que o edifício tem de apresentar determinadas características para ser erigido em "templo" - um lugar em que podem ser realizados ofícios religiosos, como missas e celebrações, e sacramentos, como a eucaristia e o batismo. Como já escrevia Claudio Pastro (1993, p.12), “o espaço sagrado é o lugar onde se celebra prioritariamente o Mistério Pascal. Demais manifestações, mesmo decorrentes desse Mistério, são secundárias e podem ser realizadas em qualquer local". Há também exigências que derivam das funções específicas de certos tipos de edifícios religiosos, como o claustro, no caso dos mosteiros, ou a capela do Santíssimo, no caso das igrejas.

A decoração surge aqui como um componente fundamental para a constituição desses espaços. Em primeiro lugar, possui um componente pedagógico, visando à transmissão da cultura católica e à evangelização dos fiéis - a Biblia pauperum (Bíblia dos pobres), o aprendizado por meio de imagens. Em segundo lugar, a arte sacra funciona como um instrumento para aproximar os fiéis do divino, despertando sua alma para a contemplação, seja por representar Jesus, Maria, os santos, apóstolos e mártires de maneira visível (uma diferença marcante para a tradição protestante), seja por oferecer um ambiente belo e acolhedor. 
Por último, como já dito, a igreja é o lugar da hierofania - a manifestação do sagrado no mundo.

Assim, na construção de espaços religiosos, arquitetura e arte se complementam e se reforçam, visto que as funções contemplativa e litúrgica se encontram em ambas. Pensemos no altar, por exemplo: precisa permitir a mobilidade ao seu redor, que torna possível os vários modos e ritos da celebração (Pastro, 1993, p.254); ao mesmo tempo em que deve estar em harmonia com o restante da igreja, de forma a permitir a contemplação e também como forma de reverenciar o divino.

Para mim, a mais importante dessas características é a beleza do conjunto. Claudio dizia que a harmonia da igreja deve refletir a harmonia de Deus. O espaço sagrado tem suas características e funções específicas, como qualquer edifício, mas a busca da beleza adquire nela um caráter único, pois oferece um caminho para a contemplação, que é o que permite a vivência plena da experiência religiosa. Para isso, arquitetura, mobiliário litúrgico e iconografia devem formar um todo coeso, harmônico e voltado ao mesmo fim.

\section{Arquitetura e arte sacra}

Pretendo aqui compartilhar um pouco da minha experiência de arquiteto que, nas últimas décadas, esteve ocupado com o projeto de edifícios religiosos, e que por essa razão teve de entrar no diálogo com os artistas plásticos no caminho para a construção desses espaços.

Para começar, uma pequena contextualização biográfica. Formei-me em arquitetura pela Faculdade de Arquitetura e Urbanismo Mackenzie, em 1981, e comecei a me aproximar da arquitetura religiosa não muito tempo depois. Aqui, a formação católica teve papel fundamental, tanto pelos interesses que despertou em mim como pelas oportunidades de trabalho a que me levou. Para isso, foi especialmente importante minha formação no Colégio São Bento e minha proximidade com os beneditinos, assim como minha participação na Igreja católica, em particular por meio do Movimento Católico Comunhão e Libertação.

Marcante também foi o encontro com o artista plástico Claudio Pastro. Conheci-o em 1980, antes do término do curso de Arquitetura, quando comecei a participar do Movimento Comunhão e Libertação. Claudio tinha um ateliê na casa que servia de sede ao movimento. Décadas depois, ele viria a se tornar um dos maiores artistas sacros do mundo, tendo produzido obras como o monumento em honra a Nossa Senhora Aparecida nos Jardins do Vaticano, a medalha comemorativa pelos 300 anos do encontro da imagem de Nossa Senhora Aparecida e, talvez seu trabalho mais importante, o projeto de ambientação do Santuário Nacional de Aparecida, mas naquele tempo ele ainda dava os primeiros passos em sua trajetória artística. Desde o início, percebi a riqueza e a força de sua arte, passando a admirar seu trabalho e percebendo a qualidade artística que apresentava, o dom de sua vocação. Era evidente sua sensibilidade e capacidade de expressar aquilo que era essencial na experiência religiosa através da arte. 
Tive a sorte de poder trabalhar com ele em inúmeros projetos. Nossa parceria entre projeto de arquitetura e arte sacra perdurou por muito tempo. Trabalhamos juntos por aproximadamente 34 anos, do início de minha carreira até sua morte, em 2016. Ao longo desse tempo, desenvolvemos juntos projetos de igrejas, capelas, conventos e mosteiros em todo o Brasil.

Mais do que descrever essa trajetória de colaboração ou listar os diversos trabalhos que fizemos, gostaria de refletir sobre o que significou, dentro da minha experiência de arquiteto, o processo criativo de um projeto de arquitetura religiosa que envolvesse a arte sacra de Claudio. Como é que um arquiteto e um artista plástico produzem, juntos, um espaço religioso funcional e belo, no qual arquitetura e arte sacra estejam ligadas e em harmonia?

\section{O trabalho com Claudio Pastro}

O primeiro projeto que fizemos juntos foi uma Casa de Campo, localizada na represa de Nazaré Paulista, em 1982. Era um local preparado para ser a sua residência, junto com a de alguns padres amigos. Alguns anos depois, projetei e construí a sua residência-atelier em Itapecerica da Serra, a Casa São Lucas.

Foram vários projetos e várias formas de trabalhar juntos depois disso. $\mathrm{Na}$ maioria das vezes, o convite para trabalhar partia do Claudio. A primeira coisa a dizer sobre o trabalho conjunto com ele é o respeito que sempre manteve em relação ao papel do arquiteto na concepção de um projeto de igreja ou mosteiro; eu, por minha vez, sempre procurei entender suas propostas para a arte do edifício. Essa relação de respeito mútuo era o que levava o edifício a ser efetivamente o resultado de um trabalho em conjunto, que integrasse o espaço e sua decoração.

Para isso, conversávamos sobre o trabalho a ser realizado, as características da obra, a adequação do programa de necessidades e as questões de uso religioso - se era uma capela ou uma igreja paroquial, por exemplo. Pensávamos juntos os espaços para o sagrado, num trabalho essencialmente colaborativo.

A parte referente à arquitetura e à construção era desenvolvida por mim. Assim, na maior parte das vezes, eu elaborava um estudo preliminar a partir das ideias levantadas em nossas discussões preliminares, e então íamos lapidando o projeto como um todo. Quando a obra estava quase pronta é que Claudio iniciava o seu trabalho. No meio tempo, ele muitas vezes repensava seu plano original, reelaborando suas ideias em resposta ao entrar em contato com o espaço acabado.

Gostaria de descrever algumas obras que fizemos juntos e que, acredito, representam bastante bem nosso processo de criação conjunta, os aspectos que privilegiamos na construção desses espaços, e os resultados de nossas colaborações.

\section{Casa São Lucas}

A primeira obra que gostaria de destacar chama-se Casa São Lucas. Essa casa foi construída como residência e ateliê do Claudio, em meados dos anos 1980. O projeto e a execução foram feitos por mim. Durante a preparação, discutimos sobre o projeto de arquitetura, levando em consideração que seria, além 
de residência, um lugar para a exposição dos trabalhos do Claudio (de fato, a sala central funcionaria como uma galeria de arte).

A residência tem um aspecto de casa de campo, com uma arquitetura que busca adequar-se ao ambiente externo. A frente, por sua vez, lembra uma capela simples do interior (Figura 1).

$\mathrm{Na}$ casa há ainda uma capela, que, além do propósito religioso, deveria servir como um modelo da arte feita por Claudio. Há nela, por exemplo, a pintura de um Cristo Pantocrator, um dos ícones preferidos do artista. A obra é característica do estilo de Claudio, que costumava insistir em que a arte sacra pós-conciliar deveria valer-se dos elementos da cultura e da arte locais. A incorporação de elementos brasileiros se mostra claramente em dois aspectos: no grande cocar indígena que aparece acima do Cristo e nos anjos com traços indígenas.

Atualmente, essa casa está sendo preparada pelas monjas beneditinas vizinhas da construção para se tornar a casa-memorial de Claudio Pastro, com croquis, biblioteca e todo o material que ele deixou.

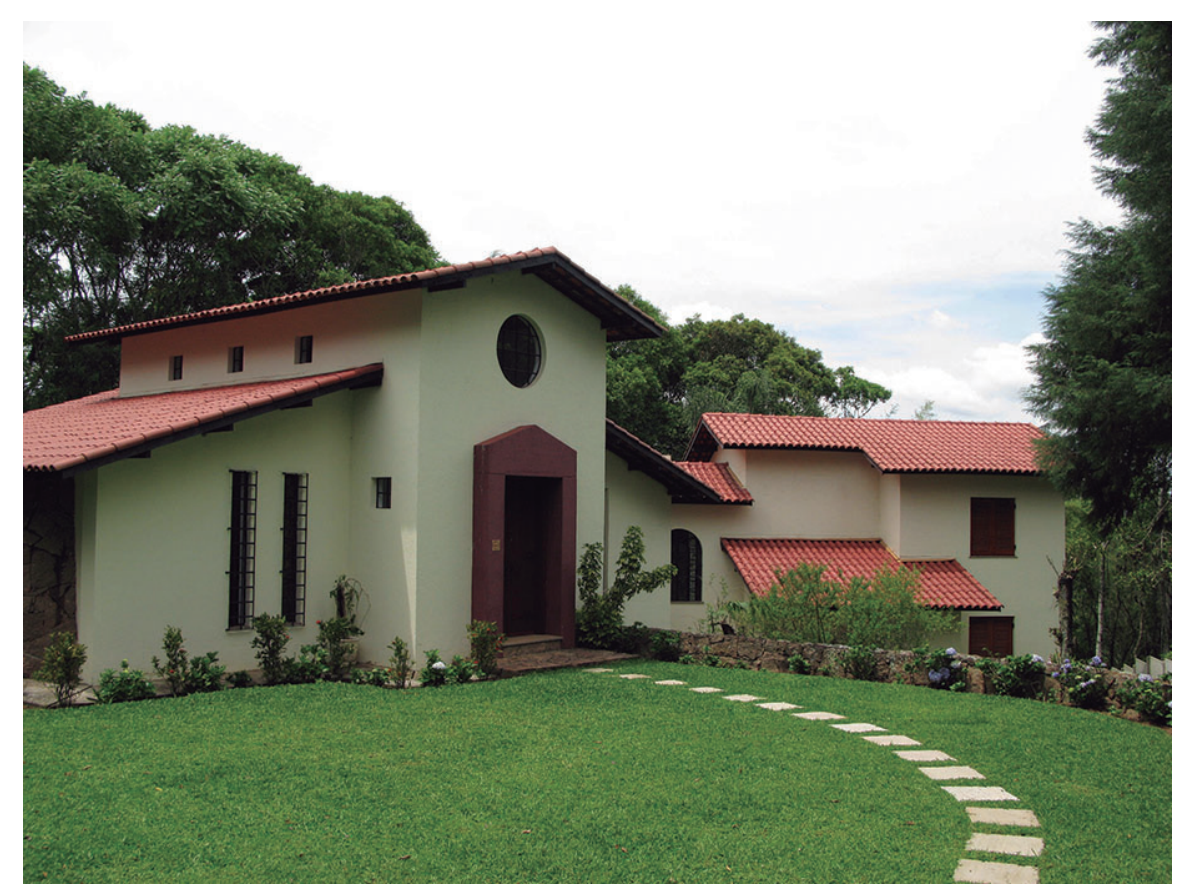

Fonte: Foto do autor.

Figura 1 - Casa São Lucas - Itapecerica da Serra (SP).

\section{Capela da Cela São José}

O segundo trabalho que gostaria de descrever é o da Capela da Cela São José, que fica em Itapecerica da Serra. Ela foi construída para os monges beneditinos do Mosteiro São Geraldo de São Paulo, na década de 1990. Como tantas vezes, o projeto de arquitetura e a execução da obra foram feitos por mim, sendo o Claudio responsável pelas pinturas. 
A capela fazia parte do núcleo inicial do mosteiro; depois de alguns anos, esse último cresceu e construiu uma nova igreja ao lado. A capela fica no centro do projeto de arquitetura, rodeada pelo refeitório, o capítulo, a sala de convivência e as celas (Figura 2).

A arquitetura austera que impusemos tem como fonte as propostas de São Bernardo de Claraval, fundador da ordem cisterciense. São Bernardo rejeitava o uso de adornos na construção e de vitrais coloridos e com figuras. Na tradição bernardina, as paredes são nuas, e o vitral é minimalista, com poucas cores e sem nenhuma figura humana. A única concessão que fazia era uma imagem de Nossa Senhora (Duby, 1990).

Essas diretrizes conduziram o projeto para a Capela da Cela São José. As paredes são completamente brancas, excetuando-se as três pinturas de Claudio. Os vitrais são transparentes com uma faixa vertical âmbar. De um lado da nave, Claudio pintou uma Nossa Senhora, e do outro, um Cristo. No átrio da igreja, colocou uma imagem de Santa Escolástica e uma de São Bento, este último carregando sua famosa Regra.

A separação entre monges e fiéis é imperceptível, o que também consta na tradição: os monges posicionam-se em volta do altar, havendo apenas um desnível no presbitério (Figura 3).

O mobiliário litúrgico é composto de sete peças de granito, com a pia de água benta representando a pia batismal logo na entrada do presbitério. $\mathrm{O}$ altar e o ambão são feitos de pedras maciças.

A única peça não trabalhada em todo o mobiliário é o tabernáculo - palavra que Claudio insistia em usar, em lugar do nome mais comum de "sacrário". O tabernáculo é o local onde Deus se apresenta, relembrando a Arca da Aliança do Antigo Testamento. Para o tabernáculo da igreja, Claudio escolheu a pedra pessoalmente, sobre a qual encaixou o tabernáculo desenvolvido por ele.

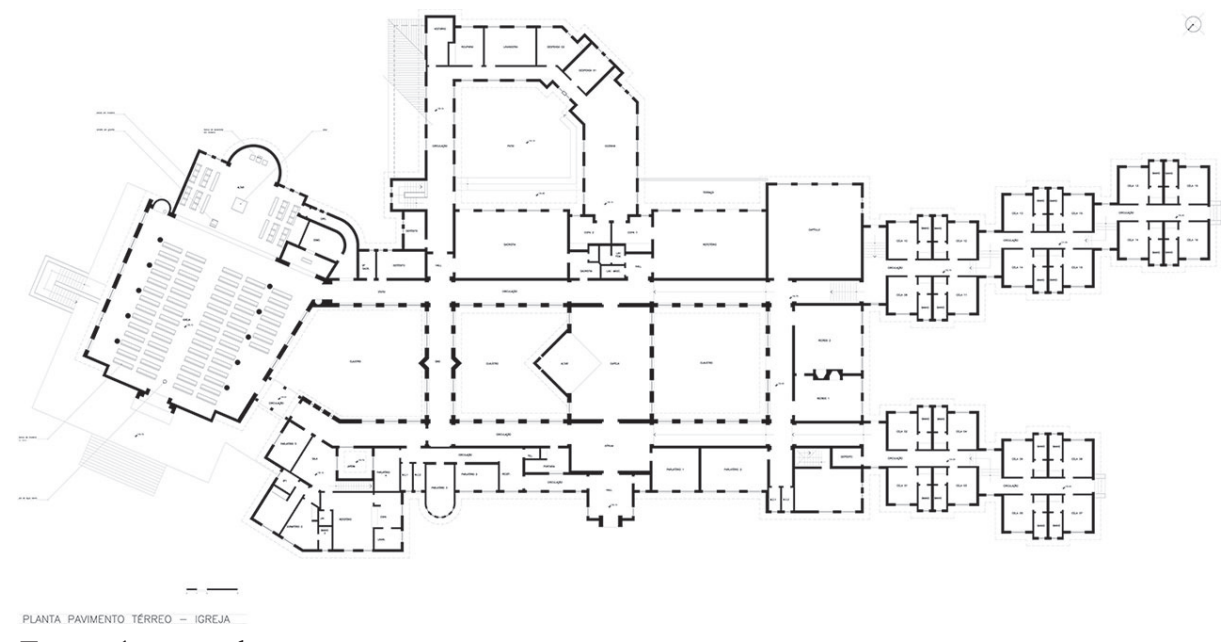

Fonte: Acervo do autor.

Figura 2 - Planta da Capela da Cela São José - Itapecerica da Serra (SP). 


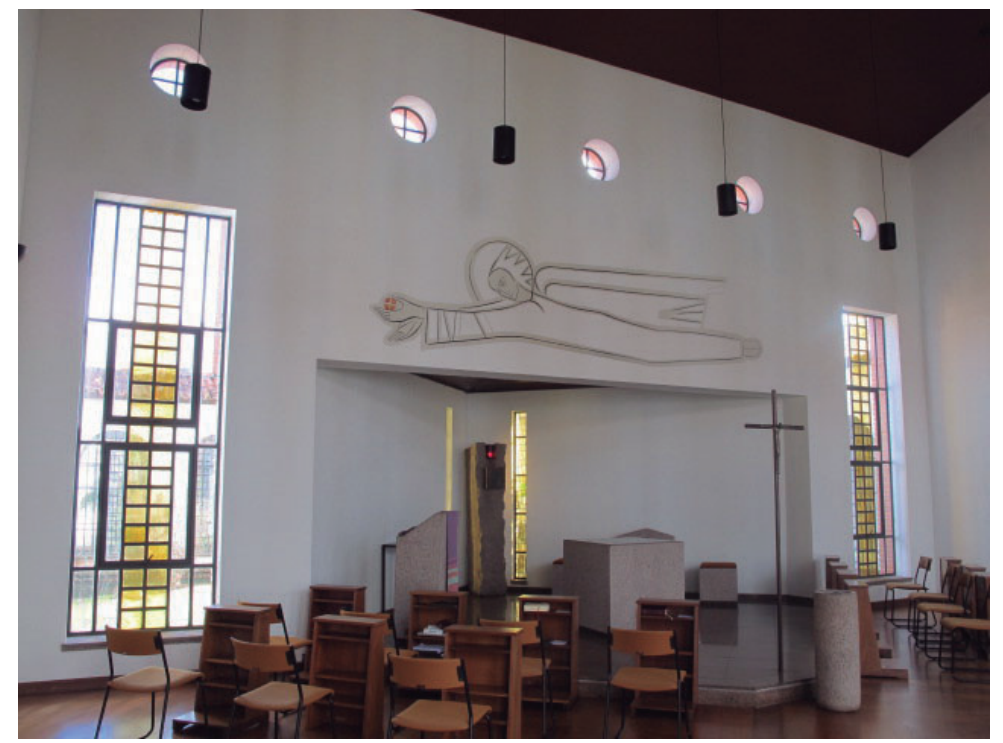

Fonte: Foto do autor.

Figura 3 - Capela da Cela São José - Itapecerica da Serra (SP).

Aqui, a austeridade prescrita por São Bernardo encontrava as exigências da arquitetura moderna. A frase de Mies van der Rohe, "Menos é mais", era também um ponto de partida para Claudio, que prezava pela simplicidade. Para ele, quanto menos coisas houvesse, mais aquilo que era realmente essencial ganharia em importância.

Procurávamos destacar as características essenciais da igreja; uma igreja que parecesse uma igreja, já que um dos problemas do pós-concílio foi a descaracterização delas. Para Claudio, era importante que o espaço da igreja anunciasse "o Senhor Jesus mesmo quando a comunidade e o celebrante estão apáticos" (Pastro, 1993, p.15).

\section{Capela do Santíssimo da Igreja São Bento do Morumbi}

Em 2004, fizemos juntos uma reforma na Capela do Santíssimo da Igreja São Bento do Morumbi, que ficava atrás do painel principal. No início da década de 1980, Claudio havia executado um grande painel para o presbitério da igreja, contando a história da salvação. A capela do Santíssimo, no entanto, continuava inalterada desde a fundação da paróquia.

O projeto foi um pedido do abade do mosteiro, D. Paulo, que desejava revigorar aquele espaço e torná-lo mais adequado para a oração e meditação individual ou de pequenos grupos. A dinâmica de readequar os espaços foi fundamental para a renovação dos espaços litúrgicos em atendimento às normas do Concílio Vaticano II.

Desenvolvi o novo projeto do mobiliário litúrgico em granito, buscando um espaço mais claro e despojado, tirando os adereços existentes. Outro objetivo dessa nova disposição era deixar em evidência a presença do Santíssimo. 
A pintura da capela contrasta fortemente com o painel feito por Claudio na década de 1980. O artista faz uma representação dos discípulos de Emaús: a história é contada no Evangelho de São Lucas, que narra o episódio dos dois discípulos que viajam com o Cristo ressuscitado sem, contudo, reconhecê-lo, até que Ele se revela no momento de partir o pão na ceia. Claudio produziu aí sua própria representação desse tema tão caro à iconografia cristã (Figura 4).

A diferença e a evolução do seu trabalho ao longo do tempo são evidentes. Comparado com o painel original da igreja, cheio de cor e figuras, seu traço no novo painel é mais sintético, mais denso e elegante, mostrando seu amadurecimento como artista. "Criando um estilo próprio, suas composições, com os anos, foram se tornando cada vez mais simplificadas e estilizadas, tendo a força nos traços muito simples, finos e econômicos, derivados da iconografia bizantina" (Berto, 2012, p.279). Sua arte tornou-se cada vez mais densa, profunda, cheia de vida.

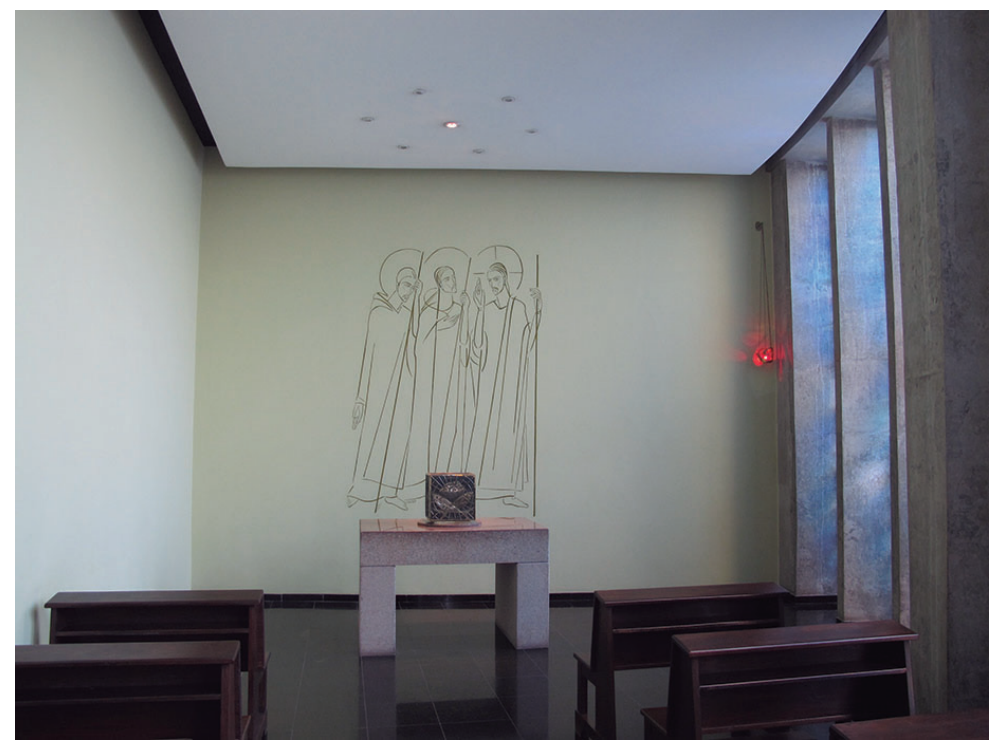

Fonte: Foto do autor.

Figura 4 - Capela do Santíssimo da Igreja São Bento do Morumbi - São Paulo (SP).

\section{Capela Monástica da Abadia São Geraldo}

Novamente a pedido do abade, D. Paulo, realizamos o projeto de reforma da capela monástica da Abadia São Geraldo, em 2006. Esse local é uma capela de uso dos monges, onde se realizam os ofícios diários da vida beneditina.

Desenvolvi o projeto de arquitetura, o mobiliário e o vitral, e Claudio ficou a cargo das pinturas. Os trabalhos, porém, foram feitos de maneira integrada: desde o início, houve entre nós um diálogo intenso sobre os aspectos estéticos do ambiente, bem como da questão litúrgica.

Claudio queria atualizar o espaço de acordo com os cânones do Concílio Vaticano II. Todo o espaço foi estruturado em torno da faixa principal, na qual 
se encontra o mobiliário litúrgico. O piso dessa faixa é de granito polido, representando o caminho do cristão rumo a Cristo, e o restante da capela é de madeira. Toda a igreja se organizou a partir dessa proposta. O caminho tem início com a pia batismal logo na entrada, simbolizando o início do percurso da vida cristã (como um peregrino). Depois, vem o ambão, a palavra de Deus. Finalmente, temos o altar, onde se realiza o sacrifício eucarístico. A dinâmica do espaço foi toda determinada pela vivência cristã - batismo, palavra e eucaristia.

O projeto de arquitetura teve a preocupação de readequar todo o espaço dentro desse novo contexto, produzindo uma mudança geral no ambiente de oração e celebração. $\mathrm{O}$ espaço foi tornado mais simples, de forma a promover uma atmosfera contemplativa. Monges e fiéis estão no mesmo nível, sem um desnível separando-os, indicando que o caminho é o mesmo para todos os cristãos, independentemente da vocação. O mobiliário litúrgico é de mármore. Claudio gostava de utilizar pedras, que, para ele, relembravam o altar do sacrifício no Antigo Testamento. À direita da capela, em um nicho, localiza-se o tabernáculo.

A pintura principal é um Pantocrator colocado no fundo da capela, que é a primeira coisa que se vê quando se entra na capela. Claudio era um profundo entendedor de teologia e simbologia/iconografia cristãs, e sua arte estava profundamente arraigada nessa tradição - simbologia presente em materiais, cores, formas e imagens que empregava (Torres, 2007, cap. 4).

Claudio valorizava especialmente o ícone bizantino do Cristo Pantocrator, uma tradição pouco observada na Igreja Romana, que prefere o Cristo na Cruz. O Pantocrator começa a ser retomado na Europa apenas na metade do século XIX, e foi Claudio o primeiro a trazê-lo ao Brasil. Esse ícone representa Jesus em sua glória - Deus onipotente, Senhor Todo-Poderoso, rei em seu trono. A mão esquerda carrega as Sagradas Escrituras, enquanto a direita faz um gesto de bênção; os dois dedos erguidos indicam sua dupla natureza (divina e humana), e os três dedos que se tocam nas pontas simbolizam a Santíssima Trindade (De Tommaso, 2017, 2020) (Figura 5).

Por último, assim como na Capela da Cela São José, as imagens de Jesus e Nossa Senhora foram pintadas uma de frente para a outra. Claudio dizia que ambos se sustentavam para viver a experiência terrena.

\section{Igreja do Mosteivo Trapista}

A última obra que gostaria de comentar é a reforma e ampliação da Igreja do Mosteiro Trapista de Nossa Senhora do Novo Mundo, em Campo do Tenente, no Paraná. Esse foi um dos últimos trabalhos que fizemos em parceria, em 2016, mas infelizmente Claudio não pôde trabalhar até o final, pois faleceu naquele mesmo ano.

Os monges trapistas precisavam ampliar a igreja do mosteiro: esta era muito pequena, e não comportava o número de frequentadores das missas de domingo. Até onde pudemos colaborar, foi um projeto bastante dialogado, em que 


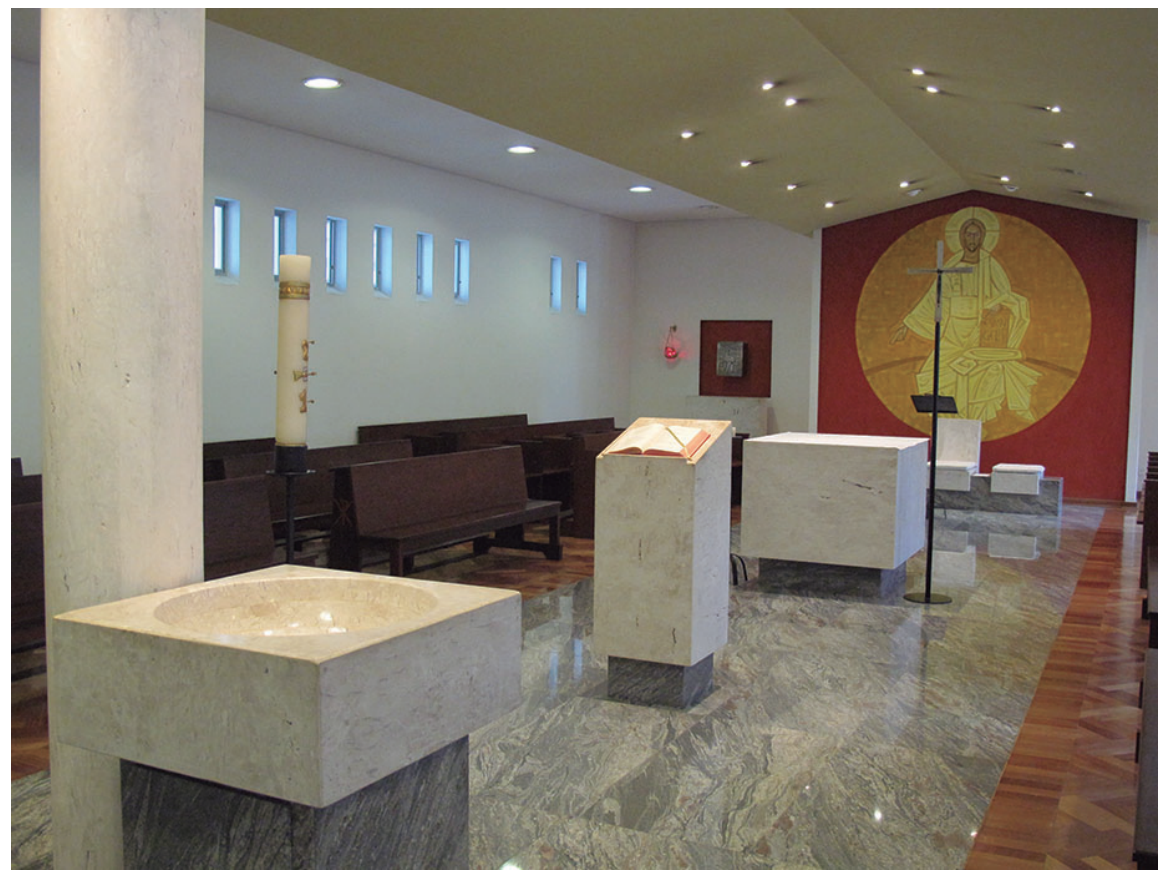

Fonte: Foto do autor.

Figura 5 - Capela Monástica da Abadia São Geraldo - São Paulo (SP).

a parte arquitetônica e artística foram pensadas de maneira conjunta, de forma a garantir uma unidade à igreja.

Como sempre, nosso projeto partia da compreensão das necessidades e da dinâmica da comunidade, na busca de uma solução arquitetônica que levasse em conta o binômio forma e função. Em nossa última visita, passamos o dia no mosteiro, conversamos com a comunidade e estabelecemos os pontos principais que deviam ser atendidos no projeto.

Optamos por não demolir toda a igreja, preservando a história e tradição do mosteiro. Originalmente em forma piramidal, a solução que encontramos foi retirar uma das faces da pirâmide e, a partir daí, criar uma nave para os fiéis (Figura 6).

Apresentei o primeiro desenho da igreja ampliada para o Claudio, para que pudesse começar a desenvolver a proposta iconográfica. Claudio já tinha feito uma primeira intervenção nessa igreja na década de 1980, ao fazer o mobiliário litúrgico e um ícone de Nossa Senhora. Esse ícone foi mantido na estrutura da igreja, e ele pensava em restaurá-lo. O retábulo no final da igreja seria usado para fazer um painel.

O mobiliário litúrgico que foi desenvolvido no projeto arquitetônico segue as mesmas indicações do Claudio para o projeto da Capela Monástica da Abadia São Geraldo. Com a diferença de que não há uma pia batismal propriamente, visto ser essa uma capela monástica, onde não se realizam casamentos e batismos. Ainda assim, a pia de água benta tem a função de relembrar que pela 
água do batismo entramos na igreja. Depois, segue a mesma sequência do ambão e do altar, relembrando o percurso cristão.

Também houve uma releitura de vários elementos da tradição cisterciense, com a disposição das três janelas na fachada (simbolizando a Trindade), a forma triangular do telhado, e a simplicidade dos materiais, almejando a austeridade defendida por São Bernardo.

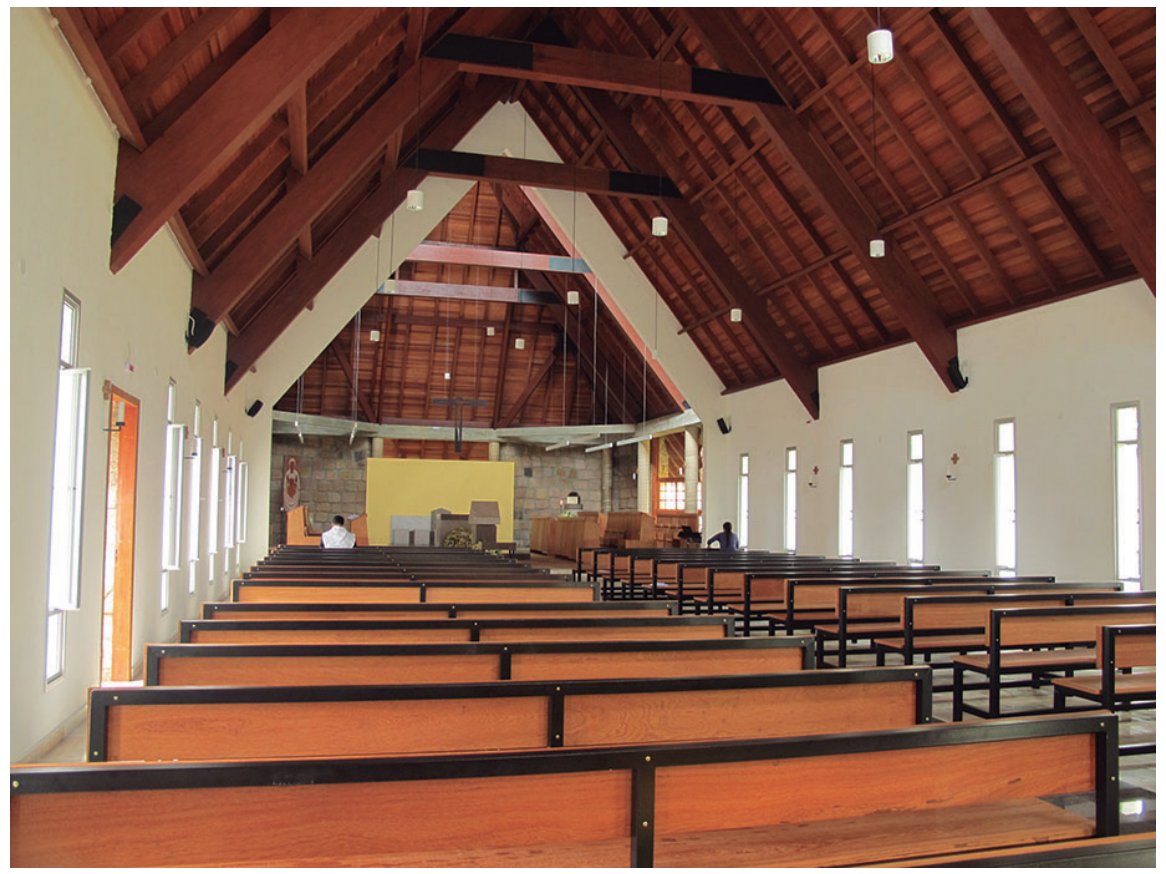

Fonte: Foto do autor.

Figura 6 - Igreja do Mosteiro Trapista - Campo do Tenente (PR).

\section{Conclusão}

Claudio e eu trabalhávamos em vários projetos quando de sua morte, como o projeto da ampliação da capela da Trapa, no Paraná, a entrada da igreja Santa Generosa, em São Paulo, e a Capela da Casa de Retiro das Irmãs Marcelinas, em Santana do Parnaíba. Para alguns destes trabalhos, Claudio havia feitos desenhos e esboços; em outros casos, foi preciso encontrar soluções que se mantivessem próximas dos projetos que havíamos pensado juntos.

Se a experiência de trabalhar com ele demonstra alguma coisa, é que a criação de espaços religiosos depende fundamentalmente de um diálogo entre arquitetura e arte sacra. É um diálogo em que não há prevalência de uma sobre a outra, mas uma relação de complementaridade. Arquitetura e arte sacra formam um todo harmônico, que ajuda na utilização do espaço para a oração, a meditação, a liturgia e as celebrações.

Claudio foi um grande mestre. Por obras e palavras, deu exemplo do que deve guiar a criação de espaços religiosos: a preocupação com as necessidades da 
comunidade; um conhecimento profundo dos aspectos litúrgicos e da tradição cristã; e uma permanente atualização diante das novas dinâmicas da vida da Igreja e das necessidades do homem de hoje.

Uma das características de Claudio era sua contínua alegria por sua vocação. Era um homem de muita fé e de certeza, firme em suas convicções, mas também dócil para mudar de ideia, na busca da beleza e funcionalidade. A marca de seu traço ficará para sempre na história da arte do Brasil e da Igreja.

Agradecimentos - Gostaria de agradecer o convite da Profa. Dra. Marina Massimi para participar deste evento, e ao prof. Luciano Migliaccio, coordenador da mesa, pela oportunidade de participar deste diálogo sobre arte e arquitetura sacra, que é um dos temas principais do meu trabalho.

\section{Referências}

BERTO, J. P. A arte a serviço do sagrado: a arte sacra de Cláudio Pastro (1948-) e o santuário nacional de Nossa Senhora da Conceição Aparecida. In: VIII ENCONTRO DE HISTÓRIA DA ARTE. 2012, Campinas.

DE TOMMASO, W. S. Claudio Pastro: Um artista pós Vaticano II. Revista de Ciberteologia: Teologia e Cultura, ano XIII, n.53, p.109-38, 2017.

. O Cristo Pantocrator: Da origem às igrejas no Brasil, na obra de Cláudio Pastro. São Paulo: Paulus Editora, 2020.

DUBY, G. São Bernardo e a arte cisterciense, trad. Roberto Leal Ferreira. São Paulo: Martins Fontes, 1990.

ELIADE, M. O sagrado e o profano. Trad. Rogério Fernandes. São Paulo: Martins Fontes, 1992.

PASTRO, C. Arte Sacra: O espaço sagrado hoje. S.l.: s.n., 1993.

TORRES, M. M. M. S. O Cristo do Terceiro Milênio - A Visão Plástica da Arte Sacra Atual de Claudio Pastro. São Paulo, 2007. Dissertação (Mestrado em Artes) - Programa de Pós-Graduação em Artes, Universidade Estadual Paulista "Júlio de Mesquita Filho".

RESUMO - A função da arquitetura é projetar espaços que atendam às diversas necessidades humanas. No caso da arquitetura religiosa, essa tarefa exige necessariamente a aproximação com a arte sacra. É somente por meio de uma interlocução harmoniosa entre essas duas áreas que se pode chegar à criação de edifícios que cumpram suas funções litúrgica e contemplativa. Neste artigo, descrevo minha experiência de trabalho como arquiteto em parceria com o artista plástico Claudio Pastro, apresentando alguns dos principais trabalhos que realizamos juntos ao longo de 34 anos - entre capelas, conventos, mosteiros e igrejas -, e discuto nosso processo de criação conjunta desses espaços.

PALAVRAS-CHAVE: Arquitetura religiosa, Arquitetura sacra, Arte sacra, Arte religiosa, Claudio Pastro. 
ABSTRACT - The function of architecture is to design spaces that meet the diversity of human needs. With religious architecture, this task requires an approximation with sacred art. Only through a harmonious interlocution between these two areas is it possible to create buildings that fulfill their liturgical and contemplative functions. In this article, I describe my work experience as an architect in partnership with artist Claudio Pastro, outlining some of the main works we have done together over 34 years - including chapels, convents, monasteries, and churches - and discussing our process of joint creation of these spaces.

KEYWORDS: Sacred architecture, Religious architecture, Sacred art, Religious art, Claudio Pastro.

Ubiratan J. A. Silva é arquiteto, bacharel em Arquitetura pela Faculdade de Arquitetura e Urbanismo da Universidade Presbiteriana Mackenzie. @ - ubiratan@labora.arq.br / https://orcid.org/0000-0002-6232-0179.

Recebido em 15.5.2020 e aceito em 5.3.2021.

I Universidade Presbiteriana Mackenzie, Faculdade de Arquitetura e Urbanismo, São Paulo, São Paulo, Brasil. 